\title{
ACCIDENT SERVICES AND THE ORTHOPAEDIC SURGEON*
}

\author{
J. C. SCott, Oxford, England
}

The orthopaedic surgeons claim a right to the treatment of injuries of the locomotor system. These make up about 75 per cent in any unselected group of accidents. Consequently he should have also the responsibility for the organisation covering the treatment of injuries.

This is a natural sequel to the gradual acceptance of two things: first that fractures come within the orbit of the orthopaedic surgeon, and secondly, that it is unsound to distinguish, from the point of view of organisation and treatment, between fractures and major soft-tissue injuries and make a break in the bone an essential "open sesame" to all the wonders of the orthopaedic department.

\section{INCIDENCE AND TYPES OF ACCIDENT}

I will so far as is possible avoid the temptation to dwell on figures, but it is essential to have some idea of the size and nature of the problem. The increased importance of injuries to the community and to the profession is both absolute and relative. The absolute increase is obvious: the relative can be exemplified in many ways: for example, from 1936-39 diphtheria was the leading cause of death up to the age of ten; in 1949 diphtheria caused 1 per cent and accidents 37 per cent in boys and 22 per cent in girls. Technical improvements in diagnosis and treatment have made it possible to keep alive many seriously injured patients, in particular those with head injuries and also the old and infirm; these have created new problems of their own. The increase in the relative importance of accidents is a trend which seems likely to continue. There is nothing to suggest any contrary tendency; indeed it seems that in the perfect worldsterilised, bacteriologically speaking, by the ideal antibiotic, and with all congenital abnormalities eliminated by selective breeding-apart from those required to treat injuries the only medical specialists required will be the obstetricians and, I am sure, the psychiatrists.

Let us consider very briefly the three main classifications of injury in order of ascending importance.

In 1955 it was estimated (Royal Society for the Prevention of Accidents) that industrial accidents caused four times as many man-days lost as labour disputes. Twenty per cent were hand injuries, and compensation alone in these cost $£ 3,000,000$. This, of course, takes no account of cost of treatment, loss of productivity, etc. Road accidents caused 5,526 deaths in 1955 out of a total 18,663 deaths due to accidents. The cost of road accidents, estimated by the Royal Society for the Prevention of Accidents, was $£ 172,000,000$. Domestic accidents are more common than either of the other two. Since 1943 there have been 1,000 more fatal casualties each year in the home than on the roads, and fewer home accidents are fatal.

The problem of accidents and their treatment is certainly large and broad. What is our share, having regard to the responsibilities that we as orthopaedic surgeons have accepted, and how should we tackle it?

\section{ORGANISATION}

We build on the examples and experience of the past, and this seems to be a field of surgery in which progress has been made in two distinct ways: 1) by the advancement of knowledge and technical skill, and 2) by development of organisation. The first is of great importance in any branch of surgery but the second is of greater importance in accidents

* Part of a lecture delivered on October 2, 1958, in the Instructional Course preceding the Annual Meeting of the British Orthopaedic Association at Oxford. 
than in any other field; with a chronic or even a subacute condition the patient and the doctor can usually choose the surgeon, but when a serious accident has taken place this is not the case and the patient is swept into the organisation and is dependent upon it for the standard of his treatment. It is essential not only to have the people with the technical skill available to treat injuries but to have the organisation which will ensure that this skill is available to those who need it when they need it. This is the problem and it involves the fractured phalanx just as much as the severe multiple injuries, and the rehabilitation of a common minor injury is just as important as the less common severe one. The basic organisation should not be designed for any special selection of cases or set of circumstances.

The type of organisation of the accident service attached to the general hospital, where the orthopaedic surgeons treat all (and only) injuries to the locomotor system but accept responsibility for the organisation of the treatment of all injuries, was mentioned in the British Orthopaedic Association Memorandum of 1943 as having been started in Oxford, and we now have seventeen years' experience of its operation. I wish briefly to describe what that organisation consists of and how it has evolved into what seems to be a satisfactory pattern of an accident service.

\section{THE OXFORD ACCIDENT SERVICE}

The Accident Service at the Radcliffe Infirmary serves the United Oxford Hospitals (the teaching hospital group) and deals with a population of about 600,000 . We receive all patients injured in accidents and accept responsibility for the standard of their treatment. We treat all injuries to the locomotor system, burns and septic fingers. There are three consultant orthopaedic surgeons devoting approximately half time to this work, one of whom is constantly available, and one neurosurgeon who spends half his time in the Accident Service. Otherwise no consultant is directly attached to the service, but all other departments are asked to deal with injuries in their own field. The patient with multiple injuries always remains in the accident service. The patient with single injuries not involving the locomotor system usually goes to the department concerned. More than 90 per cent of casual patients attending the accident service out-patient department (otherwise and unfortunately known as the casualty department) come within the purview of the accident service; the others are referred to the appropriate departments. Of accidents leading to admission only about 5 per cent do not involve either the locomotor system or the skull or both. Of all the patients nearly 25 per cent have a head injury, one-third (32.7 per cent) of whom also have other injuries. About 16.8 per cent of the head injuries require surgical intervention; of these patients 32.1 per cent are accompanied by other injuries. We have sixty beds, and by great efforts manage to keep, most of the time, within our proper limits. The average length of stay last year was 3.9 days; the turnover is rapid. We have six residents, including two registrars and one senior registrar, but not including the neurosurgical registrar who is attached to the accident service. The daily attendance in the fracture and out-patient clinics is approximately 170 . Two physiotherapists are attached to the service, and one almoner. We have in-patient and out-patient diagnostic indices on punch cards, with separate cards for all hand injuries. Three secretaries are responsible for our records. The diagnostic index and adequate secretarial assistance are essential to the efficient running of the service and to the availability of the records for analysis. Through the generosity of the Nuffield Provincial Hospitals Trust, a research grant pays for an additional registrar and a research assistant, which enables all members of the service to devote some time and thought to the abstract problems they encounter.

We have found that this type of accident service works well; it has been applied with little modification to five general hospitals in this area with satisfactory results. It requires a reasonable amount of interdepartmental goodwill and cooperation; this is of course true of any broadly based service. 


\section{FUTURE REQUIREMENTS}

The application of organisations of this type with suitable local modifications on a national basis is an essential step to dealing adequately with all types of injuries. They should be based on teaching and general hospitals and be responsible for a definite area, determined by the population to be served and the facilities and staff provided to serve it. Division of the country (particularly large cities), with clear indications to the ambulance drivers as to where these services are centred, should be an important part of the organisation.

This type of work is most interesting and responsible. It is not sufficiently organised or recognised at present to attract enough of the right kind of young people to it. This is not surprising, considering the conditions under which many have to work. There is no place for the consultant who is not prepared to do his share. We have claimed as orthopaedic surgeons a right to deal with injuries to the locomotor system, and have, at the same time, accepted the responsibility of teaching the young and of seeing that the organisation is effective and the standard of treatment high. We are inevitably under fire from two directions. In some places surgical colleagues in other specialities resent and obstruct efforts to make progress with the organisation of an accident service; and on the other hand there is a feeling in other circles, both in the profession and at the Ministry of Health, that as a group we have not pulled our weight; that too many are concerned with nominal control and leaving the work to junior people, the very thing that has been the bugbear of "casualty" work for so many years. Any orthopaedic surgeon who cannot do any better than that should bow himself out of the field of accident surgery now. 